\title{
Information Technology and Organizational Change: The Role of Context in Moderating Change Enabled by Technology
}

\author{
Mahmoud Watad \\ Monmouth University \\ West Long Branch, NJ 07764 U.S.A. \\ Tel (908) 571-3663 \\ Fax (908) 571-3656 \\ Email: mwatad@mondec.monmouth.edu
}

\author{
Sonia Ospina \\ New York University \\ 40 W. 4th St., Room 600 \\ New York, NY 10003 U.S.A. \\ Tel (212) 998-7478 \\ Email: sospina@is2.nyu.edu.
}

\begin{abstract}
This study uses data from 140 Information Systems projects implemented in public organizations to analyze the role of organizational context in moderating change enabled by the introduction of computer-based technologies. The analysis supports the notion that neither technology nor managerial action alone can be considered deterministic forces in shaping organizational change and consequently in determining the outcomes of the introduction of IT. The findings provide some evidence to suggest that as managers mature with the use of technology, they will be in a better position to coordinate the human and the technological aspects of organizational change. Additionally, the findings indicate that while managers seek alignment between the organizational mission and the use of computer-based information systems, there is a narrow and limited application of information technology to solve organizational problems.
\end{abstract}

Keywords

Technology, organization, learning, change, public, context, computers 


\section{INTRODUCTION}

Organizational change does not take place in a vacuum. It occurs in particular settings which respond to change dynamics sensitive to factors such as the nature of the job, and the social and technical conditions framing both intentions and perceptions. This article explores the role organizational context plays in moderating the changes associated with the introduction of Information Technology (IT) in public service organizations. We argue that technology in general, and IT in particular, can not be considered a deterministic force in shaping organizational change; instead, change is moderated by many contextual factors emerging in particular organizational settings.

While organizational context itself is a difficult construct to operationalize, it is possible to study particular circumstances under which interactions take place and decisions are made in organizations. The combination of these defines the specific background that, in conjunction with managerial action, affects planned change. In this article we use "organizational mission" and "stage of automation" (i.e. the level of maturity of the organization in using computer-based technology) as operational indicators of context.

The analytical strategy to explore the role of context in mediating the relationship between IT and organizational change consists in assessing the impact of these two contextual variables in 140 Information Systems projects implemented in 14 municipal organizations. These projects have in common the introduction of the same type of technology (all projects introduced technology based on communication and information storage devices) and the same type of managerial judgment (all interventions were premised on a managerial decision to introduce such devices). Assuming then, that managerial action and technological availability were relatively constant, we analyze the role of mission and stage of automation in affecting the reported changes.

If the same type of technology is introduced in the same public-sector decision-making environment, and it produces different organizational impacts, then the organizational context may in fact be critical to understand change associated with the introduction of information technology. Indeed, for the cases studied, the contextual variables analyzed did influence the impacts resulting from the introduction of IT, as reported by the managers responsible for the introduction of the projects. ${ }^{1}$ This provides evidence to support the emerging perspective of organizational change (see Section 2), by highlighting the interconnected effect of managerial action, technological availability and organizational context.

The practical value of our conclusions lies in supporting the notion that technology does not automatically determine the desired consequences in a change process. Instead, it enables the outcomes to emerge according to conditions which are context specific. Thus to assume an automatic relationship between introducing a specific technology and achieving a specific outcome may be shortsighted. Therefore, when introducing a new technology, managers must monitor its use, as well as provide the necessary adjustments for getting the most out of its introduction. Ultimately, a successful introduction of information technologies requires a careful

\footnotetext{
${ }^{1}$ The perceptions of public managers regarding the impacts associated with IT tap perceived rather than actual impact. Literature on Information Systems support and accept this approach (Danziger and Kraemer, 1986; Kraemer et al, 1993).
} 
consideration of the contextual factors which may affect the way the new technology is understood, used and adapted to achieve the desired benefits. This is particularly important in the case of public organizations, where the permeability to the political environment may influence the context specific circumstances to be considered in the managerial decision-making process (Rainey, 1991).

\section{INFORMATION TECHNOLOGY AND ORGANIZATIONAL CHANGE}

Markus and Robey (1988) identify three organizational paradigms that help explain how change enabled through information technology affects organizations. ${ }^{2}$ They are: technological determinism, the organizational imperative, and the emergent perspective of organizational change. Technological determinism views information technology as an exogenous variable that determines the behavior of organizations and their members in a generic way. In this view, the consequences of manipulating a given technology will always be the same, independent of actors and contexts. Hence the notion that for any given technological intervention there will be a predictable outcome.

The organizational imperative approach to change reflects the strategic choice paradigm of management theory. It assumes that managers can control the process of change directly, based on their search for rational solutions to organizational problems. In this view organizational actors have unlimited technological choices to produce a desired impact. While technological determinism downplays managerial choice, the organizational imperative approach assumes that the latter is the critical factor in understanding the link between information technology and organizational change.

Finally, the emergent perspective attributes change to the "unpredictable interaction of technological features and actors' intentions" (Markus and Robey, 1988). In this view, the aggregate effect of participant action, technological artifacts and organizational context determines the actual consequences of the intervention. If neither the technology itself, nor the rational manager, him or herself, totally control the process of change, other contingencies which affect possible outcomes must be considered in the analysis and in the management of change. This highlights the role of context, broadly defined as the set of circumstances or facts that surround a particular event or situation.

All three perspectives of change reviewed above share the assumption that IT is an organizational intervention or form of planned change. Yet the emergent perspective has the advantage of assuming that there are differences between "planned" change and the "actual" change which may emerge (Goodman and Burke, 1982). While both the organizational imperative approach and technological determinism provide some insights, their frames are insufficient to understand change enabled by information technology in organizations.

The organizational imperative approach assigns too much weight to rationality and managerial control over the change. It downplays the fact that information technology by itself is a resource

\footnotetext{
2 The roots of this linkage go back to Leavitt and Whisler (1958). In their landmark article "Management in the 1980's, "they speculated about the impact of IT on organizations, suggesting a "radical reorganization of middle management levels" and an increase in productivity as "fewer people...do more work."
} 
brought to organizations from the external environment. Since managers are not the creators of the technology they are bringing in, and they do not have control over the evolution of the technology as artifact, they can only control its application. Furthermore, to fully control its use, managers must have perfect understanding of it, and the users must modify their skills continuously to adapt instantly to the evolving technology. These preconditions to automatic adjustment are not possible in the real world. At least the available literature does not support their existence neither in the private nor in the public sector. Managerial action is a necessary but not a sufficient factor to explain organizational changes produced by the introduction of IT.

Technological determinism also falls short in its explanations of the dynamics of change, in particular when the task is complex and the environmental demands are numerous. This paradigm overemphasizes the independent role of technology and underemphasizes its social nature. This perspective is premised on a view of technology as an object that has measurable features independent of who is manipulating it (Woodward, 1965; early Perrow, 1967; and Thompson, 1967). In contrast, revisionist contingency theorists ${ }^{3}$ have emphasized the subjective nature of technology, defined by the way participants interpret it in specific social contexts (Dornbush and Scott 1975; Weick, 1969). The latter view claims that technology itself is less a force determining organizational outcomes (Noble, 1984), and more a mediating factor affected in turn by other social and political processes which represent material and social determinants of change (Davis and Taylor, 1976; Perrow 1983). Indeed, if technology is a social object, its applications may be sensitive to the context of the technological intervention itself. In fact, the organizational setting will play a major role in providing the "meanings" assigned to technology.

For both those who espouse the revisionist approach of contingency theory and the emerging paradigm of change, a given technology could have a different definition and could be treated differently by specific organizational participants. Moreover, if technology may be defined by the context of its use, then its consequences will be affected or moderated by the context in which it is introduced. For example, Barley (1986), studied how identical CT scanners (a computer-driven technology) introduced into two different radiology departments (in two different hospitals) affected the structure of these departments. His conclusion was that "identical technologies can occasion similar dynamics and yet lead to different structural outcomes" (Ibid, $P$ 105). To explain his results, he argued that technology is a social object that may produce consequences shaped by the context of the technological intervention.

Olson and Turner's work (1986) has also supported the emergent view of change. These authors argue that the impact of information technology on organizations is the result of a complex set of interrelated choices driven by technological availability and managerial assumptions regarding technology. In their view, the effect of IT on organizational components does not follow one single and predictable direction, nor is there a single dimension of change which can be directly linked to IT interventions.

While there is clear cause-effect relationship in the technological and the strategic choice views of change, the emergent perspective highlights the importance of interrelated factors, thus

\footnotetext{
${ }^{3}$ Contingency theory (Lawrence \& Lorch, 1967; Pugh et al., 1969; Blau \& Schoenmherr, 1971; Jenkins, 1978) postulates that organizational structure is contingent on the type of work performed and on the environmental demands placed upon the organization. The revisionist group updates this theory by relaxing the direct cause-effect relationship proposed earlier.
} 
proposing a matrix type rather than a linear relationship between information technology and organizational change. It is the interaction of organizational context, participant actions, and technological artifacts that determines the actual consequences of the IT intervention. A thorough analysis of the organizational impacts associated with an information technology intervention requires thus direct attention to the context in which technology is introduced. This goal underlies the analytical strategy of this article.

\section{THE RESEARCH SETTING: IT INTERVENTIONS AND REPORTED IMPACTS}

To provide a brief overview of the projects studied, in this section we describe the interventions, their impacts, the stage of automation, and the type of mission performed by the organization in which they were implemented. We will use this information to analyze the impact of "mission" and "stage of automation" on the changes managers reported.

\section{The intervention}

Data about the information system projects were obtained from reports submitted by city managers to the Mini-Micro Computer Coordinating Council. This is a voluntary committee formed by computer managers and staff of all city agencies. The reported projects were implemented in municipal agencies delivering services which ranged from human and enforcement services to community development, environmental and capital services, and citywide support services. For example, a pilot project implemented by the Housing Inspector Office introduced the use of radio-based handheld computers in an effort to reduce the inspectors' time spent in the office and traveling from the office to inspection sites, thus increasing the time spent performing inspections and changing the direction of the information flow.

\section{The impact of change}

The classification used in this article to describe the organizational impacts of the studied interventions is based on an elaborate framework which is fully developed and explained elsewhere (Watad, 1993). In this framework the introduction of IT into an organizational setting can produce two types of impacts: it may affect other organizational elements, such as the organization's structure, or it may affect organizational outcomes associated with effectiveness, such as the level of productivity. These two sets of dimensions are depicted in Figures 1 and 2.

Figure 1 presents the critical elements of an organization which may be affected by change: structure, technology, people, tasks and goals, and environment (Scott, 1987; Leavitt, 1965). Technology is the body of knowledge, methods, and tools employed in carrying out specific tasks. Tasks are units of work performed for the organization to realize its goals. Organizational structure refers to authority and responsibility lines, patterns of communication, as well as the norms, values, and symbols emerging from the organization's activities. People refers to the capabilities, motivations, intentions and commitment of individuals available to the organization. And finally, environment includes external social, economic, and cultural factors that influence 


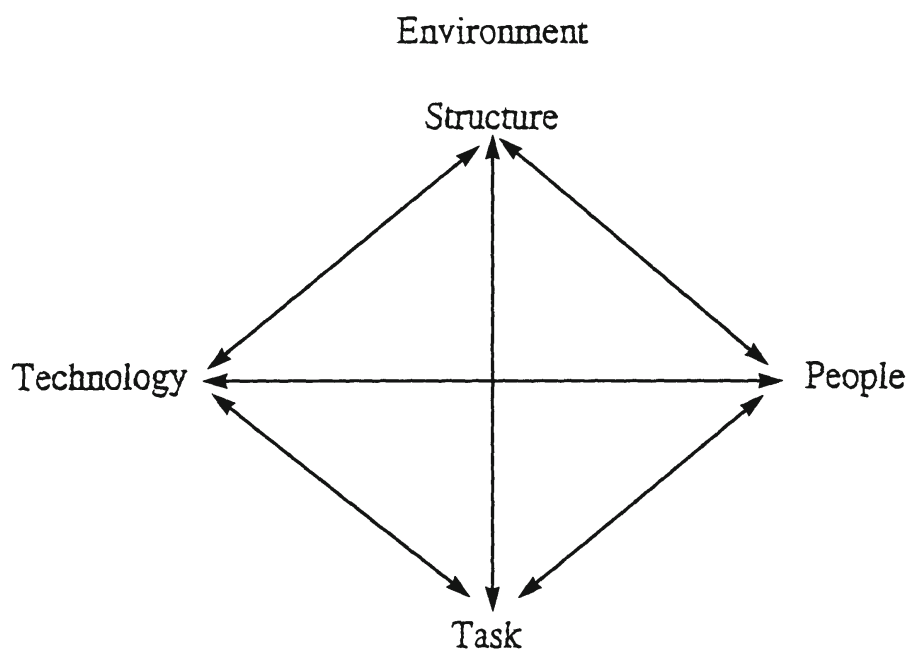

Figure 1 Organizational Elements Model

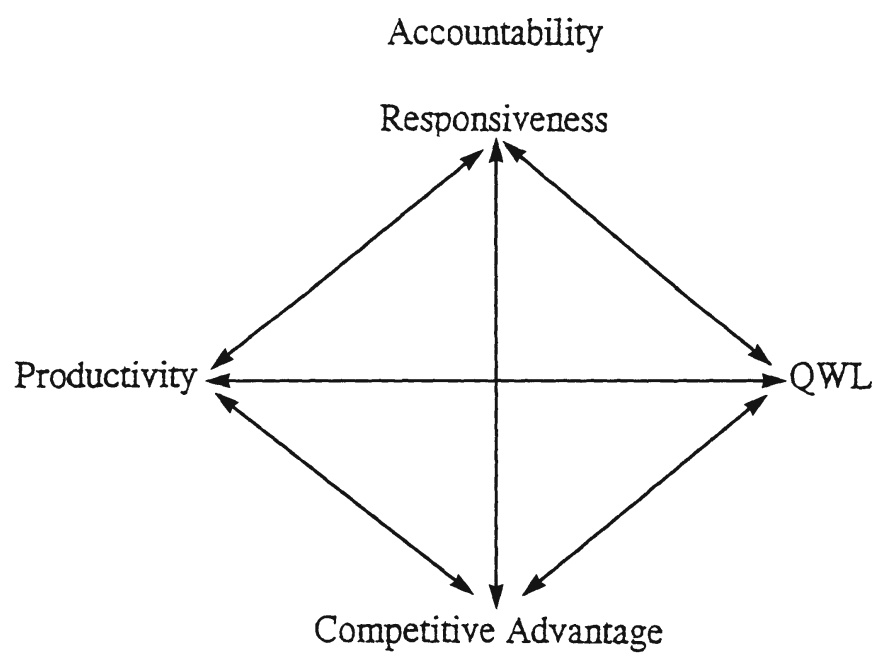

Figure 2 Organizational Outcomes Model 
an organization's activity.

In contrast to the elements, organizational outcomes refer to effectiveness criteria. ${ }^{4} \mathrm{~A}$ review of the literature on the organizational impacts of Information Technologies suggests that the wide array of criteria associated with organizational performance can be classified in one of four major outcome themes, as depicted in Figure $2 .^{5}$ These are: quality of work-life (QWL), responsiveness, competitive advantage, and productivity. A fifth external outcome of concern to public organizations is accountability toward its environment. Quality of work- life deals with employees' well-being. Responsiveness relates to the speed of delivery and the provision of information to satisfy customers. Competitive advantage includes efforts to improve the quality of the product or the service. Productivity is the ratio of inputs to outputs with respect to processing time and operating costs. Accountability refers to the organization's capability to explain its actions to its constituencies (Bozeman and Straussman, 1990).

An impact in one element may trigger a chain effect which has consequences on one or all of the others. For example, a manager may bring IT into a unit to change the method to perform a task. Benefits such as 'making the task easier to complete' or 'obtaining greater control over the task, may require modifications in other elements, such as the people performing the task. Employees may need training to learn the new method. Job duties and job titles may change, thus affecting the organization's structure. Organizational outcomes are equally interdependent. For example, changes that seek higher productivity may cause unintended transformations in the quality of work life; or an organization which seeks higher responsiveness may achieve this at the expense of harming its competitive advantage.

Our analysis focused on the benefits reported by managers after the introduction of IT in the studied projects. These were classified according to whether they represented impacts related to organizational outcomes or to organizational elements (Watad, 1993). Table 1 summarizes the impacts associated with IT as reported by managers who participated in the study. It shows, for example, that in $70 \%$ of the 140 projects, managers reported 'reduction of processing time' as a benefit of the intervention. This represents a change in the organizational outcome of Productivity. In contrast, only in $2 \%$ of the projects did managers report that the IT introduction 'improved morale' or 'reduced stress' of the organizational participants. This represents a relative absence of change in the organizational component of People. These frequencies provide the background for the analysis of the role of context, which is the primary focus of this article.

\section{The context of change}

While there are many possible contextual factors to consider in the introduction of IT, this article focuses on two, stage of automation and mission. ${ }^{6}$ The first variable, stage of automation,

\footnotetext{
${ }^{4}$ Organizational theorists agree on the centrality of effectiveness but they disagree on its definition (Heffron, 1989). Campbell (1977) has identified thirty measures of organizational effectiveness. Heffron (1989) has added five outcome measures for public organizations.

${ }^{5}$ For a description of this framework and a review of the literature sustaining its validity, see Watad, 1993.

${ }^{6}$ We considered other variables such as business function and locus of decision-making. However, in order to develop the argument presented in this article, analysis was kept as simple as possible.
} 
Table 1 Frequency Distribution for Impact Variables (maximum frequency is 140)

\begin{tabular}{|c|c|c|}
\hline Impact Variable & Frequency & $\%$ \\
\hline T4 Streamlining Operations & 136 & $97 \%$ \\
\hline S1 Division of Work & 135 & $96 \%$ \\
\hline K2 Method Alteration & 133 & $95 \%$ \\
\hline K6 Access to Information & 110 & $79 \%$ \\
\hline P2 Processing Time & 98 & $70 \%$ \\
\hline K1 Ease of Task Execution & 97 & $69 \%$ \\
\hline K7 Control over Work & 87 & $62 \%$ \\
\hline K4 Accuracy in Task Execution & 60 & $43 \%$ \\
\hline T1 Acquiring Knowledge & 58 & $41 \%$ \\
\hline A1 Accountability & 55 & $39 \%$ \\
\hline T2 Process Alteration & 54 & $39 \%$ \\
\hline P3 Reducing Cost & 52 & $37 \%$ \\
\hline R1 Delivering Service & 34 & $24 \%$ \\
\hline P1 Increasing Output & 30 & $21 \%$ \\
\hline T3 Decision Making & 27 & $19 \%$ \\
\hline R3 Providing Information & 26 & $19 \%$ \\
\hline C2 Quality of Service & 23 & $16 \%$ \\
\hline S3 Communication Patterns & 19 & $14 \%$ \\
\hline E3 Inter-Org'1 Relationship & 18 & $13 \%$ \\
\hline W1 People's Skills & 12 & $9 \%$ \\
\hline R2 Knowledgel Customers & 12 & $9 \%$ \\
\hline K5 Task Consolidation & 11 & $8 \%$ \\
\hline E2 New Relationships & 9 & $6 \%$ \\
\hline E1 Contact $\backslash$ Environment & 7 & $5 \%$ \\
\hline K3 Scheduling Flexibility & 7 & $5 \%$ \\
\hline S2 Work Flow Alteration & 7 & $5 \%$ \\
\hline Q1 Stress & 3 & $2 \%$ \\
\hline S4 Centralization & 3 & $2 \%$ \\
\hline Q3 Morale & 3 & $2 \%$ \\
\hline S6 Impersonal Control & 2 & $1 \%$ \\
\hline S5 Decentralization & 2 & $1 \%$ \\
\hline C1 Linking services & 2 & $1 \%$ \\
\hline Q2 Job Satisfaction & 2 & $1 \%$ \\
\hline C3 New Product \Service & 1 & $1 \%$ \\
\hline S7 Shifting Power & 1 & $1 \%$ \\
\hline W3 Initiation & 1 & $1 \%$ \\
\hline W2 Abstract Thinking & 0 & $0 \%$ \\
\hline
\end{tabular}

$\mathrm{T}=$ Technology, $\mathrm{S}=$ Structure, $\mathrm{K}=$ Task, $\mathrm{W}=$ People, $\mathrm{E}=$ Environment, $\mathrm{P}=$ Productivity, $\mathrm{C}=$ Competitive Advantage, $\mathrm{R}=$ Responsiveness, $\mathrm{Q}=\mathrm{QWL}, \mathrm{A}=$ Accountability 
refers to the experience of organizational actors with information technology at the time of the intervention. Projects were either implemented to automate a manual business function or to upgrade an existing automated information system. ${ }^{7}$ These stages represent two different levels of maturity with respect to the use of information systems. The two categories embody qualitatively different experience bases with which to manage the intervention. Extensive experience and familiarity with computer-based technology, developed over time, can provide a more focused approach to implement new information technology to transform existing processes and functions. The use of this indicator as a contextual variable presumes the notion of technology as a social object which is highly sensitive to the actors' subjective perceptions of its meaning. However, there is no need to assume that managers involved in the upgrade stage are the same as those involved during first time automation. The higher level of maturity comes from the organizational learning which takes place after an organization introduces a new technology. Thus maturity refers to the organization more than to the individual managers involved in the change process.

Table 2 shows the distribution of the projects according to the "stage of automation". From a population of 140 projects, 32 projects were classified as "upgrade," while 108 were classified as "1st time automation". This distribution suggests that the use of information technologies in the organizations studied for the most part was introductory and not advanced. The fact that most projects $(77 \%)$ were introduced for the first time may be an indication of public organizations' lack of maturity with the use of IT, or it may be an indication of the lack of computing skills in these organizations.

Table 2 Two Stages of Automation

\begin{tabular}{lll}
\hline Stage of Automation & Frequency & Percent \\
First Time Automation & 108 & $77 \%$ \\
Upgrade/ Transition & 32 & $23 \%$ \\
\hline
\end{tabular}

All projects were classified

Maximum frequency is 140

The second contextual variable is the type of mission accomplished by the organization where the intervention took place. We use a service operations definition of the mission of an organization to classify the public organizations studied. Service missions ensure that collective action in organizations is geared toward providing value added through the consumption of the

\footnotetext{
${ }^{7}$ The upgrade category also included projects that were transitional in their nature but which included a previous IT base, for example, the shift from mainframe based to PC/LAN based projects.
} 
service. Thus, from the consumers' perspective, organizations may be classified into two main categories according to their mission: those facilitating services for consumers and those delivering services to consumers (Fitzsimmons and Sullivan, 1982).

The first type of organization provides services which assist consumers in achieving other ends, as in the case of transportation (getting somewhere), sanitation (maintaining public health), etc. The second type of organization provides services which, in one way or another, transform the consumer voluntarily or involuntarily, as in the case of education or health services, criminal justice agencies, etc. The basic difference between the two categories, for the purpose of this discussion, is that the first type of organization focuses on the community as whole as its prime consumer, while the second focuses on the individual as its prime consumer.

Table 3 presents the frequency distribution of the projects according to their mission. From a population of 140 projects only 37 projects resided in organizations dealing directly with the individual ("to consumer"). Ninety-two took place in "for consumer" organizations, which dealt with the community as whole. The remaining 11 were classified as citywide service projects and were therefore excluded from the analysis. ${ }^{8}$

Table 3 Mission Classification by the Target of Service

\begin{tabular}{lll}
\hline Type of Service & Frequency & Percent \\
Service to the Individual* & 37 & $26 \%$ \\
Service to the Community** & 92 & $66 \%$ \\
\hline
\end{tabular}

* To consumer

** For consumer

$8 \%$ were classified as Citywide internal services

Maximum frequency is 140

\section{RELATING CONTEXT TO ORGANIZATIONAL IMPACTS}

To explore the relationships between the contextual variables and the organizational impacts associated with IT, we conducted a subgroup analysis in two stages ${ }^{9}$. The first stage applied the

\footnotetext{
${ }^{8}$ These projects deal with functions internal to the city's operations such as the inter-agency electronic mail system.

${ }^{9}$ Two stages are necessary when projects are classified into groups, largely because some of the impacts with low variation (which were excluded) become very significant in relation to one group. For example, the task consolidation variable was excluded because its frequency in the population was only $8 \%$, but it appeared in the 2nd order group with $30 \%$ frequency. In addition, two stages are necessary because the first produces "significance"
} 
Chi-square procedure between each contextual variable and the impact variables to find significant associations. The second stage of the analysis measured the difference in the relative frequency of the occurrence of the impact variables between the subgroups ${ }^{10}$.

As an example, considering stage of automation, the first step explored if there was a significant relationship between this dimension and each of the impact variables, such as "increasing output" or "reducing processing time". For those cases where the relationship was significant, the second step then explored the number of times an impact variable was reported by managers for each of the two stages of automation. Higher frequencies would indicate the managerial focus or intentions to produce a specific type of organizational benefit as managers introduced the technology. The same logic was applied to explore the relationship of organizational mission to the organizational benefits. The results are presented below.

\section{Stage of Automation}

Table 4 summarizes the results of the analysis to answer the question of significant differences in the reported organizational impacts, between those organizations which implemented projects to upgrade an existing technology, and those which implemented projects to automate functions for the first time. In addition to those associations that were significant, the table also includes those cases where the difference in the relative frequencies between the two levels was above $10 \%$.

One may hypothesize that projects introduced for the first time may produce results which are less bold in terms of their consequences (for example, "enhancing control over work"). In contrast, those benefits produced by projects aimed at upgrading an existing automated system would have broader consequences for transforming the business functions of the organization (for example, emphasizing "increasing output"). This was in fact the case in the projects studied.

Table 4 suggests that when managers introduced IT for the first time into their units, their primary concern was reducing processing time of the operations, delivering services faster and enhancing control over work. The first two benefits represent factors directly linked to the organizational outcomes of productivity and responsiveness (see Figure 1). The underlying thread of these two benefits is a managerial desire to improve the speed with which services are produced and delivered. The third benefit, control, represents an impact on either the "structure" or the "task". This is linked to the managerial desire to enhance task execution as well as improve the monitoring of work.

Table 4 also demonstrates that when managers upgraded existing information systems their primary concern was to achieve better communication patterns, to increase output, to increase the ease of task execution, to alter the work flow, and to achieve better access to information. "Communication patterns" and "altering work flow" represent indicators of organizational structure. "Access to information" and "ease of task execution" represent indicators of the task element. The focus on these indicators represents a managerial interest

while the second reveals "magnitude".

${ }^{10}$ In this context a group of projects refers to those projects that fit a value of the contextual variable. For example, the "stage of automation" variable has two values, one for each group. Therefore, projects are divided in two groups, one is "first time automation" and the second "upgrade". 
to improve the structural patterns and task related factors in their organization. "Increasing output" is an indicator of the organizational outcome of productivity. The focus on this component represents management's concern on increasing the capacity of their production system in order to satisfy more customers.

Table 4 Impact Variables Frequencies by Stage of Automation: Comparing Impacts' Frequencies in the "Upgrade" Group Versus "First-Time Automation" Group.

\begin{tabular}{lccc}
\hline Impact Variable & Upgrade & Automation & Difference \\
S3 Communication patterns & $34 \%$ & $7 \%$ & $27 \%$ \\
P1 Increasing Output & $34 \%$ & $18 \%$ & $17 \% *$ \\
K1 Ease of task execution & $84 \%$ & $69 \%$ & $15 \%$ \\
S2 Altering work flow & $16 \%$ & $2 \%$ & $14 \%$ \\
K6 Access to information & $88 \%$ & $76 \%$ & $12 \%$ \\
R1 Delivering service & $6 \%$ & $30 \%$ & $-23 \% * *$ \\
K7 Control over work & $44 \%$ & $68 \%$ & $-24 \% *$ \\
P2 Processing time & $44 \%$ & $78 \%$ & $-34 \% * *$ \\
\hline
\end{tabular}

Number of projects in the upgrade group was 32 and in the first time automation group was 108 . The percentages in the middle columns were calculated by dividing the number of times an impact variable was perceived occurring in each group by the total number of projects in the corresponding group.

The significance level was determined by using Chi-square procedure

** significance level less than $5 \%$

* significance level less than $1 \%$

Putting these findings in theoretical perspective, it is possible to suggest that the context provided by the level of maturity, as a proxy of the stage of automation in the organization, has a direct influence on the impacts associated with the introduction of IT. This supports the emerging perspective of change. Since the same type of technology did not produce the same type of impacts in both the upgrade and the automation group, it is possible to rule out the notion that technology by itself is the driving force of the change process. Indeed, findings from the stage of automation analysis suggest that there is a difference in managers' perceptions when 
they upgrade existing automated projects than when they introduce technology for the first time. One may conclude, that when managers upgrade existing systems their focus shifts from short sighted objectives such as reducing processing time, improving delivery of services, and enhancing control over work, to more long-term objectives such as increasing the ease of task execution, improving communications patterns, and increasing output. In short, their shift from speed and control over work to ease of performing task and increasing capacity may indicate a broadening of their approach. Maturity may pave the road to a long term qualitative change in the organization, when the technology will become completely subsumed into the business operation.

\section{Organizational Mission}

Table 5 presents the findings from examining the effect of the organizational mission on the impacts associated with the introduction of IT. It reveals that in organizations which deliver services to consumers and therefore deal with the individual directly (for example a health organization), managers are more interested in affecting organizational outcomes than they are in affecting internal elements of the organization. In contrast, managers in organizations that deal with the community as a whole (for example a sanitation department), emphasize elements more than outcomes. Indeed, the first four indicators of this table represent the organizational outcomes of productivity ("increasing output"), responsiveness ("delivering service" and "knowledge of customers"), and accountability ("accountability"). In contrast, the last four indicators represent the organizational components of technology ("knowledge analysis" and "decision-making"), environment ("inter-organizational communications), and task related factors ("access to information").

For example, the frequency of occurrence of the benefit "increasing output" in organizations targeting the individuals was $38 \%$, while the frequency for community-oriented organizations was $15 \%$. There is a $23 \%$ point difference between the frequencies managers reported this impact according to the organizational mission. Furthermore, this impact seemed to be more common in organizations that provide services to individual consumers. On the other hand, managers in organizations with missions aimed at the community reported changes in organizational elements more frequently.

Some strategic thinking seems to occur in public service organizations as public managers align the IT introduction with the mission of their organizations. It is interesting to note from these findings, for example, that while organizations providing services for the community introduce technology to enhance knowledge and analysis, organizations that provide services to the individual introduce technology to be more accountable toward their environment. One possible explanation for this pattern is that the organizational context which emerges in the process of addressing the two types of mission affect managers' search for solutions. In the organization with the mission geared toward individuals, managers focus on the immediate concern of consumer needs. This forces them to find timely responses, thus focusing attention on short term solutions to the problems. In the organizations with a community-based mission, managers do not have direct consumer pressure. Long term capital projects can afford lengthier time frames for decision making. Indeed, managers in these types of organizations usually deal with large scale projects which require complex analysis and elaborate decision making to produce unstructured solutions. The pressure for effectiveness stems from internal considerations 
more than from factors in the external environment.

This interpretation is consistent with our notion that the different missions create different organizational contexts, which in turn affect the direction of change produced by the introduction of information technology. Given the same managerial decision to introduce the same type of technology in particular organizational contexts, the mission of the organization moderates the types of impacts produced during the implementation process. This represents further evidence for the emergent view of organizational change.

Table 5 Impact Variables Frequencies by Organizational Mission Type: Comparing Impacts' Frequencies in the "Individual Customer" Group Versus the "Community" Group.

\begin{tabular}{lccc}
\hline Impact Variable & Individual & Community & Difference \\
P1 Increasing output & $38 \%$ & $15 \%$ & $23 \% * *$ \\
R1 Delivering service & $35 \%$ & $18 \%$ & $17 \% * *$ \\
A1 Accountability & $46 \%$ & $34 \%$ & $12 \%$ \\
R2 Knowledge of customers & $14 \%$ & $3 \%$ & $10 \%$ \\
E3 Inter-Org'l Communications & $3 \%$ & $12 \%$ & $-9 \%$ \\
T1 Knowledge-analysis & $35 \%$ & $46 \%$ & $-11 \%$ \\
T3 Decision-making & $5 \%$ & $25 \%$ & $-20 \% *$ \\
K6 Access to information & $62 \%$ & $85 \%$ & $-23 \% *$ \\
\hline
\end{tabular}

Number of projects in the "individual" group (to consumer) was 37 and in the "community" group (for consumer) was 92. The percentages in the middle columns were calculated by dividing the number of times an impact variable was perceived occurring in each group by the total number of projects in the corresponding group.

The significance level was calculated from Chi-square analysis

** significance level less than $5 \%$

* significance level less than $1 \%$

\section{CONCLUSION}

This article provides evidence for the relevance of context to understand the organizational change associated with the introduction of IT into public-service organizations. Neither IT nor 
strategic choice alone control the change process. Instead, change is moderated by factors linked to the organizational setting. The findings presented here, therefore, support the emergent perspective of organizational change.

Awareness of the emergent perspective of organizational change can provide insights for public managers engaged in efforts to solve organizational problems by introducing new information technology. It suggests that managers must take into consideration in their managerial philosophy and style the following two paradigms of mutual adjustment: the first proposes keeping in mind the relationship between the human and the technical aspects of the production system they manage. The second proposes to focus simultaneously on the external demands posed by the environment and the internal resources required to meet these demands.

With respect to the first paradigm, the findings from the "stage of automation" analysis suggest that managers address problems and search for solutions differently, according to each level of maturity in the use of technology. This has important human resources management implications for succession planning and recruitment. For example, it may be important to consider this characteristic in the process of recruiting and training new managers, because if they lack sufficient experience with IT, this could affect their decisions about how to coordinate technological innovation with the management of human skills.

Organizational effectiveness requires the optimal coordination of people skills and technological innovation. Since public organizations tend to have more stable human resources because of institutional constrains in their staffing, public managers must be skillful both in managing human resources and in understanding information technology. In particular, they must be able to evaluate the pool of skills available and either adjust the technological innovation to such skills or provide enough training to upgrade the skills to the necessary level. In either case, the fragmentation of authority over personnel decisions typical of the public sector requires that the manager be more alert in developing these strategies to accomplish the desired coordination (Brock, 1984).

The findings provide some evidence to suggest that as managers mature with the use of technology, and as its use becomes easier, they will be in a better position to coordinate the human and the technological aspects of organizational change. In the studied projects, that managers widened their concerns for speed and control to include ease of task execution and increased communication flow represents an enhancement of the mentioned coordination efforts. It also indicates a broader concern to include both the technical and the human aspects of information technology in the change effort. This represents a better utilization of human resources and a clear integration of information technology into the managerial task.

With respect to the second paradigm, the findings from the "mission" analysis suggest that for the cases studied, there is an alignment between the organizational mission and the use of computer-based information systems. While managers in organizations with community based missions utilized an inward focus, managers focusing on missions for individual consumers utilized an outward focus. This suggests the existence of strategic thinking. However, that the focus was primarily inward in one case and outward in the other, indicates a narrow and limited application of information technology to solve organizational problems.

Organizational effectiveness requires a comprehensive approach for applying technology and a balanced focus between external and internal concerns. A localized focus will ignore --by default-- important contextual factors which, according to the emergent approach espoused in 
this paper, represent critical determinants of organizational change enabled by IT interventions. The practical result of ignoring such contextual variables will be an increase of unintended consequences associated with the introduction of IT, which may be negative in nature. This will in turn require a costly adjustment in organizational elements.

Given the recent reinventing government trends inspired by the national political climate, and the limited resources public managers face, the effective use of technology will require by necessity a comprehensive rather than a localized managerial focus. Moreover, recent literature in public management has emphasized the need to pay attention to the consumer and to develop a client orientation, to counteract the effects of an excessive focus on the internal workings of the bureaucracy (Barzelay, 1992). While this trend is welcome to balance the previous emphasis, public managers must remember that both extremes are equally problematic, and that an effective approach to public management requires a much more balanced concern with internal and external forces. An example of balance suggests investing in front line employees (internal element) so that the customers will be served better (external element).

\section{REFERENCES}

Barley, S. R. (1986) Technology as an Occasion for Structuring: Evidence from Observations of CT Scanners and the Social Order of Radiology Departments. Administrative Science Quarterly, 31, 78-108.

Barzelay, Michael, (1992) Breaking through bureaucracy: a new vision for managing in government, Los Angeles, CA: UC Press.

Blau, P. \& R.A. Schoenherr. The Structure of Organizations. New York: Basic Book, 1971.

Bozeman, B., \& Straussman, J. (1990) Public Management Strategies, San Francisco, CA: Jossey-Bass.

Brock, J. (1984) Managing people in public agencies. Personnel and Labor Relations, Lanham, MA: UPA.

Campbell, J.P. (1977) On the Nature of Organizations Effectiveness. In P.F. Goodman, J.M. Pennings, and Associates, New Perspectives on Organizational Effectiveness. San Francisco: Jossey-Bass.

Danziger, J.N. \& Kraemer K. (1986) People and Computers: The Impact of Computers on End Users in Organizations. NY: Columbia University Press.

Davis, L.e. and J.C. Taylor. (1976) Technology, Organization, and Job Structure. In R. Dubin, Handbook of Work, Organization, and Society. Skokie, IL: Rand-McNally.

Dornbusch, S.M. \& W.R. Scott. (1975) Evaluation and the Exercise of Authority. San Francisco: Jossey-Bass.

Fitzsimmons and Sullivan. (1982). Service Operations Management. New York: McGraw Hill, 1982.

Heffron, F. (1989) Organization Theory and Public Organizations: The Political Connection. Englewood Cliffs, NJ: Prentice Hall.

Goodman, P. \& Burke, L. (1982) Studies of Change in Organizations: A Status Report. In Goodman and Associates (Eds.), Change in Organizations: New Perspectives in Theory, Research, and Practice. San Francisco, CA: Jossey-Bass. 
Jenkins, W.I. (1978) Policy Analysis: A Political and Organizational Perspective. London: Martin Robinson.

Kraemmer, K., Danziger, J., Dunkle, D., \& King J. (1993). The usefulness of computer-based information to public manages. MIS Quarterly, 129-148.

Lawrence, P. R. \& Lorsch, J. (1967) Organization and Environment. Cambridge: Harvard University Press.

Leavitt, H.J. (1965) Applied Organizational Change in Industry: Structural, Technological and Humanistic Approaches, in Handbook of Organizations, pp. 1144-70, ed. James G. March. Chicago: Rand McNally.

Leavitt, H.J. and Whisler, T.L. (1958) Management in the 1980's. Harvard Business Review, November-December: 41-48.

Markus, M.L. \& Robey D. May (1988) Information Technology and Organizational Change: Causal Structure in Theory and Research. Management Science, Vol. 34, No. 5.

Noble, D. (1984) Forces of Production: A Social History of Industrial Automation. New York: Knopf.

Olson, M.H. and Turner, J.A. (1986) Rethinking Office Automation. Data Base, Summer 1986.

Perrow, C. (1967) A Framework for the Comparative Analysis of Organizations. American Sociological Review, 32, 194-208.

Perrow, C. (1983) The Organizational Context of Human Factors Engineering. Administrative Science Quarterly, 28, 521-541.

Pugh, D.S., D.J. Hickson, C.R. Hinings, \& C. Turner. (1969) The Context of Organizations Structures. Administrative Science Quarterly, 14(1): 91-114.

Rainey, H. (1991) Understanding and managing public organizations, San Francisco, CA: Jossey-Bass.

Scott, W.R. (1987) Organizations: Rational, Natural, and Open Systems. Englewood Cliffs, NJ: Prentice-Hall.

Thompson, J. D. (1967) Organizations in Action. New York: McGraw-Hill.

Watad, M. (1993) Dissertation: The organizational benefits associated with the introduction of information technologies in public service organizations. Ann Arbor: UMI

Weick, K.E. (1969) The Social Psychology of Organizing. Reading, Mass.: Addison-Wesley.

Woodward, J. (1965) Industrial Organizations: Theory and Practice. London: Oxford University Press.

\section{BIOGRAPHIES}

Mahmoud Watad is Assistant Professor of Management in the School of Business Administration at Monmouth University. His research focuses on information management; information technology diffusion and implementation; organizational effectiveness and change; and the determinants (i.e. culture) and consequences (i.e. economic development) of technological change. After obtaining a B.S. in mechanical engineering and a M.S. in materials engineering, he earned a Masters in public affairs from the University of Texas at Austin, and a Ph.D. in management from New York University. Before joining Monmouth University, he worked as director of computing resources in New York City government for more than five years. 
Currently he is studying the strategic use of telecommuting in the state of New Jersey, and its degree of diffusion in the state's economy.

Sonia Ospina is Associate Professor of Public Administration in the Robert Wagner Graduate School of Public Service at New York University. Her main interests are organization and management theory; public management; human resources management; and sociological perspectives on work, employment and social policy. Her work has appeared in Business and Economic Review, Review of Public Personnel Administration, Public Productivity and Management Review, Handbook of Public Administration and Gestión y Politica Pública. She is the author of Illusions of Opportunity: Employee Expectations and Workplace Inequalities (forthcoming) from Cornell University/Industrial Labor Relations Press. She has an M.S. in policy analysis and public management and a Ph.D. in sociology, both from the State University of New York at Stony Brook. 